\title{
Inspection Scheduling Programs Analysis of Amine Reboiler Heat Exchanger Using Risk- Based Inspection API 581 Method
}

\author{
Khoirunnisa M. Syawalina ${ }^{1}$, Dwi Priyanta ${ }^{2}$, Nurhadi Siswantoro ${ }^{3}$ \\ (Received: 21 August 2020 / Revised: 16 September 2020 / Accepted: 10 December 2020)
}

\begin{abstract}
- in the oil and gas industry, the purification and handling of oil and petroleum gas, the cycle of warmth transformation is expected to isolate the $\mathrm{H} 2 \mathrm{~S}$ and $\mathrm{CO} 2$ from natural gas with an amine. The cycle happens inside the amine reboiler which is a shell and tube heat exchanger type. Cycle liquid streaming in the Amine Reboiler are Lean Amine on the shell side (HEXSS) and Therminol-55 on the cylinder/tube side (HEXTS). With such synthetic arrangement, worked with high weight and temperature, makes the liquid into a destructive climate for Amine Reboiler. Along these lines, an exact review and planning program is needed to guarantee equipement's life, guaranteeing the protected establishment and wellbeing of laborers. Thus, it is important to direct a danger assessment for shell and tube heat exchanger gear utilizing the Risk-Based Inspection technique which alludes to the API RP 581. The danger of Amine Reboiler is a mix of the Probability of Failure (PoF) and the Consequence of Failure (CoF). From the PoF and CoF acquired, the HEXSS hazard level on the danger lattice at the RBI date and RBI plan date are ordered as Low Risk and Medium Risk. While the danger level of HEXTS on danger network at RBI date and RBI plan date both are ordered as Medium-High Risk. At that point the prescribed date to do the assessment is January $1,2020$.
\end{abstract}

Keywords — amine reboiler, CoF, PoF, risk-based inspection, risk

\section{INTRODUCTION}

$\mathrm{T}_{1}$ he oil and gas refinery industry in Indonesia is one of the industries that contributed up to 215 trillion rupiahs in 2018. The refinery industry revenue exceeds the target set at 160.6 trillion rupiahs with an amount of 800,000 barrels per day [1]. Although currently the world community is exploring and developing renewable energy, the role of oil and natural gas in the world, especially in Indonesia, cannot be ignored. Fossil fuels remain an important source of energy in Indonesia.

One of the essential equipment used in the refining process on oil and gas processing plants is an amine reboiler. Amine Reboiler is a type of shell and tube heat exchanger [2]. The function of an amine reboiler is to remove hydrogen sulfide $\left(\mathrm{H}_{2} \mathrm{~S}\right)$ and carbon dioxide $\left(\mathrm{CO}_{2}\right)$ from natural gas using an amine solution. Amine reboiler is a very important item because it works at high pressure and temperature with an explosive fluid [3]. If a failure occurs, it will cause the system to shut down and harm the surrounding environment to the employees working around [4].

An example of an explosion in the oil and gas industry caused by a failed heat exchanger was the explosion at the Tesoro Refinery Anacortes, Washington

Khoirunnisa Mahdiyah Syawalina, Department of Marine Engineering, Institut Teknologi Sepuluh Nopember, Surabaya 60111, Indonesia. E-mail: khoirunnisa16@mhs.ne.its.ac.id

Dwi Priyanta, Department of Marine Engineering, Institut Teknologi Sepuluh Nopember, Surabaya 60111, Indonesia. E-mail: priyanta@its.ac.id

Nurhadi Siswantoro, Department of Marine Engineering, Institut Teknologi Sepuluh Nopember, Surabaya 60111, Indonesia. E-mail: nurhadi@ne.its.ac.id on April 2, 2010. From this incident, seven employees died. Based on the investigative report, it was found that the cause of the explosion was a shell and tube heat exchanger which had been operating for 38 years [5]. Two heat exchangers that were close to each other were ruptured. The cause of the heat exchanger rupture is High-Temperature Hydrogen Attack (HTHA) which occurs due to the material being exposed to hydrogen at high temperatures and pressures. HTHA causes the material from the heat exchanger (carbon steel) to fracture in the welding area of the heat-affected zone. The explosion occurs in the shell and causes hydrogen and naphtha with a temperature of more than $500^{\circ} \mathrm{F}$ to release into the atmosphere where the two gases are ignited immediately after contact with the atmosphere [5].

Therefore, the oil and gas processing industry is one industry that requires strict attention in terms of safety. One example of regulations regarding petroleum management is Government Regulation no. 11 of 1979 which controls the safety of work in oil and gas processing must be obeyed. Furthermore, based on the Regulation of the Minister of Energy and Mineral Resources No. 18/2018 indicates that equipment installed in gas plants must carry out inspections either on a time basis or on a precautionary basis. According to the latest revision of Work Procedure Guidelines - 041 SKK Migas Indonesia on the maintenance of oil and gas production facilities by implementing scheduled inspections and planned maintenance.

To comply with regulations related to the oil and gas industry and reduce the risk of damage to the amine reboiler, a risk analysis should be performed, and carry out scheduled inspections. One method of approach in determining the inspection interval and the inspection methods is Risk-Based Inspection (RBI) [6]. The RBI method defines risk as the result of a combination of 
both Probability of Failure (PoF) and the Consequences of Failure (CoF) [7]. The RBI method was used because the time-based inspection method was no longer relevant as quality control. This is because each piece of equipment has different problems and changes with time so that the decline in the quality of the equipment cannot be predicted accurately [8]. Inspection planning in the RBI method is focused on classifying what to do during the inspection, the inspection method, the inspection location, and the appropriate inspection interval [9].

\section{METHOD}

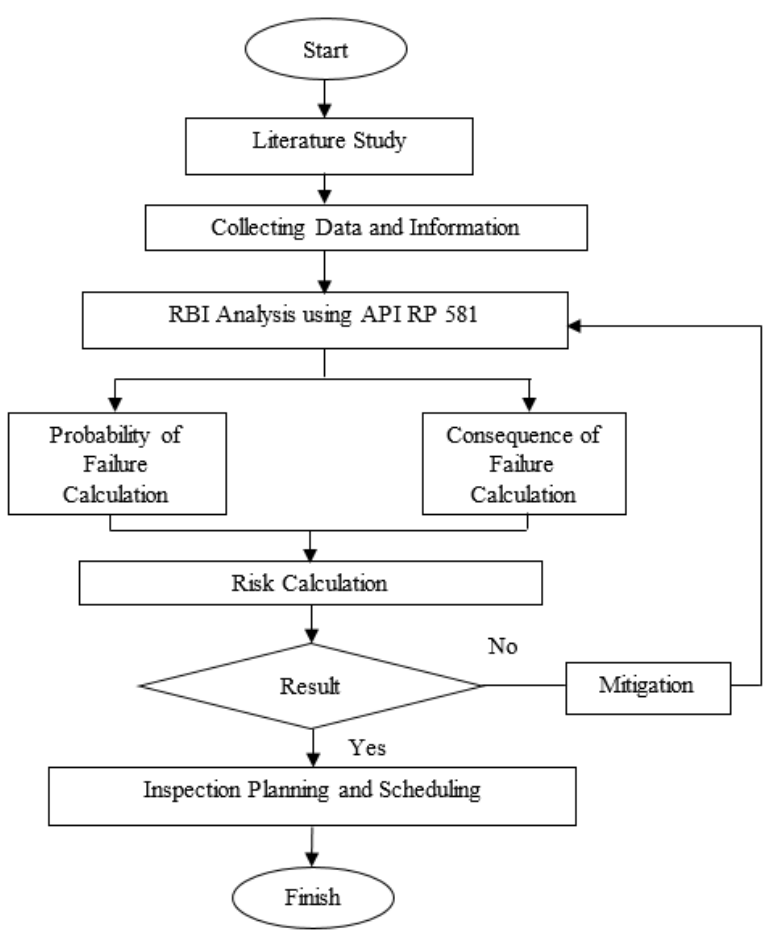

Figure. 1. Research methodology flowchart

In planning inspections using the API 581 RBI method is using the results of the risk analysis. The risk value is obtained by combining the Probability of Failure (PoF) and Consequence of Failure (CoF) [9].

To perform RBI analysis, it is necessary to collect data and information related to the analyzed equipment from supporting data. These data are obtained from PFD, P\&ID, heat material balance sheets, process datasheets, mechanical datasheets, and factory acceptance reports.

After collecting the necessary data and information, the first step in conducting an RBI analysis is to calculate the probability of failure. The estimated failure probability value is calculated based on a combination of the damage factor (Df), the generic failure frequency (gff), and the management system factor $\left(\mathrm{F}_{\mathrm{MS}}\right)$ which is formulated as:

$P_{f}(t)=g f f \cdot D_{f}(t) \cdot F_{M S}$

The next step is to calculate the consequences if a failure occurs. The consequences of failure are categorized into two, these are consequences based on the affected area and financial consequences.
The area-based consequences of failure are calculated according to the following steps:

Step 1. Determine the released fluid and its properties, including the release phase.

Step 2. Select a set of release hole sizes to determine the possible range of consequence in the risk calculation.

Step 3. Calculate the theoretical release rate.

Step 4. Estimate the total amount of fluid available for release.

Step 5. Determine the type of release, continuous or instantaneous, to determine the method used for modeling the dispersion and consequence.

Step 6. Estimate the impact of detection and isolation systems on release magnitude.

Step 7. Determine the release rate and mass for the consequence analysis.

Step 8. Calculate flammable/explosive consequence.

Step 9. Calculate toxic consequences.

Step 10. Calculate non-flammable and non-toxic consequences.

Step 11. Determine the final probability-weighted component damage and personnel injury consequence areas.

The tube bundles consequence is calculated using financial consequences, the consequences are estimated by calculating the total costs resulting from an unscheduled shutdown $\left(\mathrm{C}_{\mathrm{f}}^{\text {tube }}\right)$ with the following equation:

$\mathrm{C}_{\mathrm{f}}^{\text {tube }}=$ Cost $_{\text {prod }}+$ Cost $_{\text {env }}+$ Cost $_{\text {bundle }}+$ Cost $_{\text {maint }}$

where Cost $_{\text {prod }}$ is the cost of lost production revenue due to downtime, Cost env $_{\text {is }}$ the cost of the impact on the environment Cost $_{\text {bundle }}$ is the cost of replacing equipment and Cost $_{\text {maint }}$ is the cost of maintenance.

The Cost $_{\text {prod }}$ is determined using equation (3) below:

$\operatorname{Cost}_{\text {prod }}=$ Unit $_{\text {prod }} \cdot\left(\frac{\text { Rate }_{r a d}}{100}\right) \cdot D_{s d}$

where Rate $_{\text {red }}$ is the bypass with rate reduction, Unit prod $_{\text {is }}$ the unit production cost, and $\mathrm{D}_{\mathrm{sd}}$ is the time (days) to repair during an unplanned failure.

Cost bundle $_{\text {can }}$ be assumed using equation (4) below:

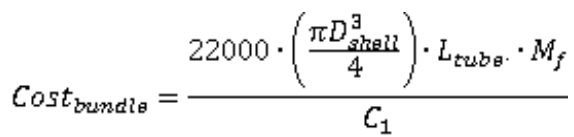

where $\mathrm{D}_{\text {shell }}$ is the outside diameter (inch), $\mathrm{L}_{\text {tube }}$ is the length of the equipment (feet), and $\mathrm{M}_{\mathrm{f}}$ is the tube material cost factors. Cost $t_{\text {maint }}$ is assumed to be the same as the cost of replacing equipment.

The calculated probability and consequence values are then entered into the risk equation.

Risk $=P_{f(\mathrm{t})} \cdot C_{f}$ 
the probability and consequence values are then categorized based on the ranges set by API RP 581 so that when they are entered into the risk matrix, the risk level of the equipment can be known.

The known risk value is then compared with the predetermined risk target. If the calculated risk value exceeds the risk target, it is necessary to take mitigation measures and carry out risk analysis again until the risk calculation results can be accepted. The results of the comparison will form the basis for determining an appropriate inspection schedule and inspection method. The flow of RBI analysis in this study can be seen in Figure 1.

\section{RESULTS AND DISCUSSION}

\section{A. Probability of Failure (PoF)}

The estimated probability value is calculated based on (1) where each parameter is as follows:

\section{a. Generic failure frequency (gff)}

The value of generic failure frequency is based on the type of equipment which in this study is a heat exchanger and the component types are HEXSS and HEXTS, which is $3.06 \times 10^{-5}$.

b. Management system factor ( $\left.F_{M S}\right)$

In determining the value of the management system factor (FMS) using a series of questions and surveys that refer to API RP 581 Part 2, Annex 2.A. and the total score obtained is entered in equation (6).

$$
F m s=10^{(-0 ; 02 \text { pscore }+1)}
$$

where pscore is the percentage form of the total score obtained from the company using equation (7).

$$
\text { pscore }=\frac{\text { Score }}{1000} \cdot 100 \text { [wit is } 100 \% \text { ] }
$$

with a total screening, the score is 500, the FMS value is obtained based on equation (6) is 0.9333 .

\section{c. Damage factor (Df)}

Active damage mechanisms in accordance with the operating conditions, environment, and material equipment amine reboiler are thinning, stress corrosion cracking, and external. Of the 21 defined damage factors, based on the amine reboiler condition, there are 5 damage factors that have the possibility to cause failure.

\section{- Thinning Damage Factor}

All equipment needs to be evaluated against thinning damage factors. Thinning is caused by various mechanisms such as corrosion and erosion factors. Corrosion factors are caused by compounds contained in process fluids such as $\mathrm{CO}_{2}, \mathrm{H}_{2} \mathrm{~S}, \mathrm{H}_{2} \mathrm{O}$, $\mathrm{CL}_{2}$, and amine. The erosion factor is caused by a combination of the velocity of the fluid flow and the size of the particles in the fluid.

There are 2 types of thinning, general thinning, and localized thinning $[\mathrm{X}]$. General thinning is corrosion characterized by a corrosion area of more than $10 \%$ and a depth of less than $1.27 \mathrm{~mm}$.
Localized thinning is corrosion characterized by a corrosion area of less than $10 \%$ and a depth of more than $1.27 \mathrm{~mm}$. In this analysis, the type of thinning that occurs based on the type of corrosion is localized thinning.

For thinning calculations on the shell side of Amine Reboiler ABC-E-0101, based on the results of the screening criteria in API RP 581 Part 2 Annex 2.A, the corrosion factor is caused by sour water corrosion, amine corrosion, and $\mathrm{CO}_{2}$ corrosion. Sour water corrosion is caused by the presence of $\mathrm{H} 2 \mathrm{~S}$ in the process fluid. Amine corrosion is caused by equipment being exposed to gas treating amine (MDEA) in the sweetening gas process. $\mathrm{CO}_{2}$ corrosion caused by the presence of $\mathrm{CO}_{2}$ and water in the process fluid and construction material is SA516 GR.70N which is carbon steel with $\mathrm{Cr}$ content $<13 \%$.

For tube side Amine Reboiler ABC-E-0101 thinning calculations because the process fluid is $100 \%$ therminol-55, the corrosion rate cannot be determined by API RP 581 Part 2 Annex 2.A. So that the corrosion rate for thinning calculations is assumed to be $0.003 \mathrm{~mm} / \mathrm{yr}$ [X DESHPANDE].

\section{- $\quad$ Stress Corrosion Cracking - Amine Cracking}

Amine cracking is a type of SCC which is defined as cracking due to a combination of tensile stress and corrosion caused by the presence of alkonolamine solution at a certain temperature. Alkonolamine solutions are commonly found in amine treating units, which are used to remove acidic compounds from hydrocarbon gases or liquids. There are 4 parameters in calculating the susceptibility of a material to amine cracking, these are: (1) the type of amine used; (2) the composition of the amine solution; (3) the operating temperature; and (4) the tensile stress level of the material.

In this study, the alkanol amine solution was methyl diethanolamine (MDEA). Where MDEA has a relatively smaller chance compared to other types of amines. The amine solution in equipment consists of $90.5763 \%$ water with content of $0.0119 \% \mathrm{H} 2 \mathrm{~S}$ and $0.2894 \% \mathrm{CO} 2$ so that it is categorized as lean amine so that amine cracking has a relatively small chance. With the PWHT (post-weld heat treatment) treatment on equipment, the susceptibility of the material to amine cracking can be reduced.

\section{- Stress Corrosion Cracking - Sulfide Stress Cracking}

Sulfide stress cracking (SSC) is a type of SCC which is defined as cracking due to a combination of tensile stress and corrosion caused by the presence of water and hydrogen sulfide. Hydrogen stress cracking occurs due to the absorption of hydrogen atoms produced by the sulfide corrosion process on the metal surface. The susceptibility of the material 
to SSC can be reduced by using PWHT (post-weld heat treatment) on the equipment.

The process fluid in equipment has a water content of $90.5763 \%$ and an $\mathrm{H} 2 \mathrm{~S}$ content of $0.0119 \%$. With the PWHT (post weld heat treatment) treatment on equipment, the susceptibility of the material to SSC can be reduced.

\section{- Stress Corrosion Cracking - HIC/SOHIC- $\mathrm{H}_{2} \mathrm{~S}$}

HIC / SOHIC - $\mathrm{H}_{2} \mathrm{~S}$ cracking stands for hydrogen-induced cracking and stress oriented hydrogen-induced cracking due to the influence of $\mathrm{H}_{2} \mathrm{~S}$. HIC is defined as a gradual internal fracture connecting adjacent hydrogen blisters on different surfaces. The susceptibility to HIC is mainly influenced by the sulfur content in the metal. The higher the sulfur content in the material, the more susceptible it is to HIC. Susceptibility to HIC is also influenced by $\mathrm{pH}$ and $\mathrm{H}_{2} \mathrm{~S}$ concentration in water. The further away from neutral $\mathrm{pH}$ and/or the higher the concentration of $\mathrm{H}_{2} \mathrm{~S}$, the more susceptible to HIC.

In this study, the Amine Reboiler ABC-E-0101 material is carbon steel with a sulfur content of $0.035 \%$ and a PWHT (post weld heat treatment) leaks. CUI will occur at temperatures of $-12^{\circ} \mathrm{C}$ and $175^{\circ} \mathrm{C}$. In the temperature range of $77^{\circ} \mathrm{C}$ to $110^{\circ}$ $\mathrm{C}, \mathrm{CUI}$ will occur at a more significant rate.

In this study, the insulation type of HEXSS Amine Reboiler ABC-E-0101 is Calcium Silicate. The CUI driver is in a marine/cooling tower drift area so that the base corrosion rate has a value of $0.095 \mathrm{~mm} / \mathrm{y}$.

The calculation result for the CUI damage factor on the shell side of Amine Reboiler ABC-E0101 is 0.3636 at RBI date and 1.1121 at RBI plan date.

\section{- Total Damage Factor Calculation}

If there is more than one damage factor mechanism, the total Df is calculated using equation (8) if the thinning is classified as local and there is no internal liner.

$$
D_{f-t o t a l}=\max \left[D_{f-g o v}^{t h i n}, D_{f-g \circ v}^{\text {extd }}\right]+D_{f-g o v}^{S S C}+D_{f-g o v}^{h t h a}+D_{f-g o v}^{\text {brit }}+D_{f-g o v}^{\text {mfat }}
$$

The results of the calculation of the damage factor that occurs in the HEXSS amine reboiler component are shown in Table 1 and the HEXTS amine reboiler component is shown in Table 2.

TABLE 1.

CALCULATION RESUlt OF HEXSS DAMAgE FACTOR

\begin{tabular}{ccc}
\multicolumn{3}{c}{ CALCULATION RESULT OF HEXSS DAMAGE FACTOR } \\
\hline Types of Damage Factor & RBI Date $(01 / 01 / 2020)$ & RBI Plan Date $(01 / 01 / 2024)$ \\
\hline Local Thinning & 1.0563 & 36.7808 \\
SCC-Amine & 71.7739 & 125.8925 \\
SCC-Sulfide & 0 & 0 \\
SCC-HIC/SOHIC-H $\mathrm{H}_{2} \mathrm{~S}$ & 35.8869 & 62.9463 \\
CUI & 0.3636 & 1.1121 \\
\hline
\end{tabular}

TABLE 2.

CALCULATION RESUlt OF HEXTS DAMAGE FACTOR

\begin{tabular}{ccc} 
& CALCULATION RESULT OF HEXTS DAMAGE FACTOR & \\
\hline Types of Damage Factor & RBI Date $(01 / 01 / 2020)$ & RBI Plan Date $(01 / 01 / 2024)$ \\
\hline Local Thinning & 0.1000 & 0.1000 \\
SCC-Amine & 166.615 & 296.018 \\
SCC-Sulfide & 71.7739 & 125.8925 \\
SCC-HIC/SOHIC- $\mathrm{H}_{2} \mathrm{~S}$ & 0 & 0 \\
CUI & 35.8869 & 62.9463 \\
\hline
\end{tabular}

treatment so that it has medium environmental severity. With a $\mathrm{pH}$ of 7.83 and $\mathrm{H}_{2} \mathrm{~S}$ concentration of $0.0119 \%$, the level of susceptibility to HIC is relatively low.

\section{- Corrosion Under Insulation (CUI)}

Corrosion Under Insulation (CUI) is a local corrosion that occurs due to the presence of water accumulating in the space between the insulation and the surface of the equipment. Collected water can come from rainwater, water seepage, condensation, deluge systems, and steam tracing

\section{d. Probability of failure calculation}

With a gff value is $3.06 \times 10^{-5}$, FMS value is 0.9333 and total Df value as in Table 1 and Table 2 , the PoF value can be calculated using equation (1). The total Df and PoF values obtained for each type of component are listed in Table 3.

\section{B. A consequence of Failure ( $\mathrm{CoF})$}

The consequence analysis of the Amine Reboiler ABC-E-0101 for the HEXSS component type uses the consequence level 1 and approaches the affected area in the form of the area burned the area of heat radiation that

TABLE 3

Calculation of Total DF AND PoF Amine Reboiler

\begin{tabular}{ccccc} 
& \multicolumn{2}{c}{ CALCULATION OF TOTAL DF AND POF AMINE REBOILER } \\
\hline \multirow{2}{*}{ Component Types } & \multicolumn{2}{c}{ RBI Date (01/01/2020) } & \multicolumn{2}{c}{ RBI Plan Date (01/01/2024) } \\
\cline { 2 - 5 } & Total Df & PoF & Total Df & PoF \\
\hline HEXSS & 72.830 & $2.080 \mathrm{E}-03$ & 162.673 & $4.646 \mathrm{E}-03$ \\
HEXTS & 166.615 & $4.758 \mathrm{E}-03$ & 296.018 & $8.454 \mathrm{E}-03$
\end{tabular}


affects humans and the area of toxic impact. As for the HEXTS component type, the consequence analysis is calculated using a financial approach based on bundle criticality which includes costs of lost production revenue due to downtime, costs of impact on the environment, and costs of maintenance and replacement of tube bundles.

a. HEXSS consequence of failure

The consequences of failure to use the affected area approaches are categorized into:

$\mathrm{CA}^{\text {flam }}=$ flammable/explosive consequence

\section{b. HEXTS consequence of failure}

$\mathrm{C}_{\mathrm{f}}^{\text {tube }}$ values are categorized into costs of lost production income due to downtime ( Cost $_{\text {prod }}$ ) using equation (3), cost of impact on the environment $\left(\right.$ Cost $\left._{\text {env }}\right)$, cost of replacing bundles (Cost $t_{\text {bundle }}$ ) obtained from equation (4), and cost of maintenance (Cost $\left.t_{\text {maint }}\right)$. From the parameters mentioned, the consequence value is obtained as shown in Table 5.

C. Risk Analysis

a. Calculate the risk value of amine reboiler

TABLE 5. CALCULATION OF HEXTS FinANCIAL CONSEQUENCE

\begin{tabular}{|c|c|c|}
\hline \multicolumn{2}{|c|}{ Financial Consequences Parameters } & Consequence (\$) \\
\hline \multicolumn{2}{|c|}{ Local Thinning } & 1.0563 \\
\hline \multicolumn{2}{|c|}{ SCC-Amine } & 71.7739 \\
\hline \multicolumn{2}{|c|}{ SCC-Sulfide } & 0 \\
\hline \multicolumn{2}{|c|}{ SCC-HIC/SOHIC- $\mathrm{H}_{2} \mathrm{~S}$} & 35.8869 \\
\hline \multicolumn{2}{|c|}{ CUI } & 0.3636 \\
\hline \multicolumn{3}{|c|}{ TABLE 6. RISK CALCULATION OF AMINE REBOILER } \\
\hline Risk & HEXSS $\left(\mathrm{m}^{2} /\right.$ year $)$ & HEXTS (\$/year) \\
\hline Risk at RBI date & $9.48 \mathrm{E}-03$ & $1,040.49$ \\
\hline Risk at RBI plan date & $2.12 \mathrm{E}-02$ & $1,848.59$ \\
\hline Risk target & 3.71 & 75,000 \\
\hline
\end{tabular}

TABLE 7. RISK CATEGORY OF HEXSS AMINE REBOILER

\begin{tabular}{ccc}
\hline Category & RBI date (01/01/2020) & RBI plan date(01/01/2024) \\
\hline PoF category & 3 & 4 \\
CoF category & $\mathrm{A}$ & $\mathrm{A}$ \\
Risk Category & $3 \mathrm{~A}$ & $4 \mathrm{~A}$ \\
\hline
\end{tabular}

$\mathrm{CA}^{\text {tox }}=$ toxic consequence

$\mathrm{CA}^{\text {nfnt }}=$ non-flammable and non-toxic consequence

The total consequence area is determined based on, the maximum value between, component damage or damage to components, with consequences that cause personnel injury or accidents to workers. Determination of the consequences of component damage, personnel injury, and the total consequences of each can be seen in equations (9), (10), and (11) below.

$$
\begin{aligned}
& \mathrm{CA}=\max \left[C A_{\text {cmd }}, C A_{\text {inj }}\right] \\
& C A_{\text {cmd }}=\max \left[C A_{\text {cmd }}^{\text {flam }}, C A_{c m d}^{\text {tox }}, C A_{c m d}^{\text {nfnt }}\right] \\
& C A_{\text {inj }}=\max \left[C A_{\text {inj }}^{\text {flam }}, C A_{\text {inj }}^{\text {tox }}, C A_{\text {inj }}^{\text {nfnt }}\right]
\end{aligned}
$$

The results of calculating the consequences of failure using the impact area approach on the HEXSS amine reboiler are listed in Table 4.
The risk values at the RBI date and RBI plan date for HEXSS and HEXTS components calculated using equation (5) are listed in Table 6.

\section{b. Risk level of amine reboiler}

- Risk level of HEXSS amine reboiler

To determine the risk level of the components HEXSS, PoF, and CoF values have been calculated categorized by API RP 581 .

After each risk parameter is known for its category as listed in Table 7 , it is then entered into the risk matrix shown in Figure 2.

- The risk level of HEXTS amine reboiler

To determine the risk level of the components HEXTS, PoF, and CoF values have been calculated categorized by Table 8 . 


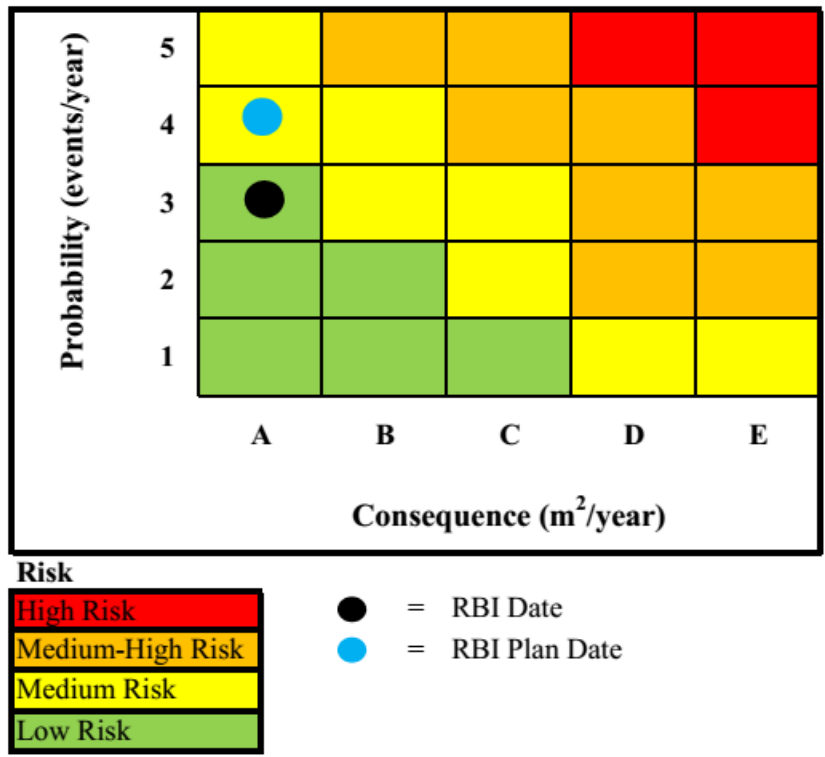

Figure. 2. Risk Matrix of HEXSS Amine Reboiler

After each parameter knew the risk category as listed in Table 8, later incorporated into the risk matrix shown in Figure 3.
D. Inspection Plan

\section{a. Inspection Intervals}

Scheduling the inspection is an activity that determines appropriate inspection intervals for components analyzed (Amine Reboiler).

TABLE 8

RISK CATEGORY OF HEXTS AMINE REBOILER

\begin{tabular}{ccc}
\hline Category & RBI date (01/01/2020) & RBI plan date (01/01/2024) \\
\hline PoF category & 4 & 4 \\
CoF category & $\mathrm{C}$ & $\mathrm{C}$ \\
Risk Category & $4 \mathrm{C}$ & $4 \mathrm{C}$
\end{tabular}

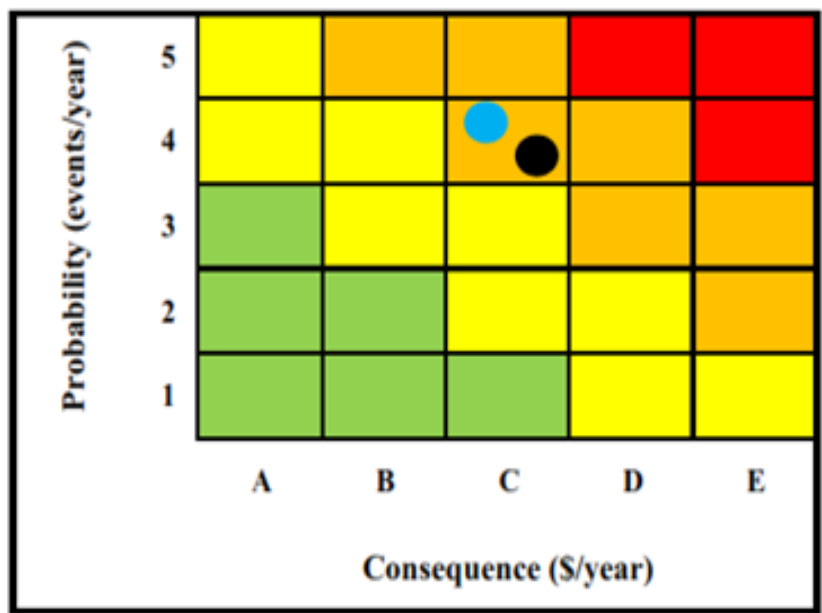

Risk

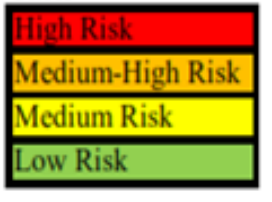

$=$ RBI Date

$=$ RBI Plan Date

Figure. 3. Risk Matrix of HEXTS Amine Reboiler 


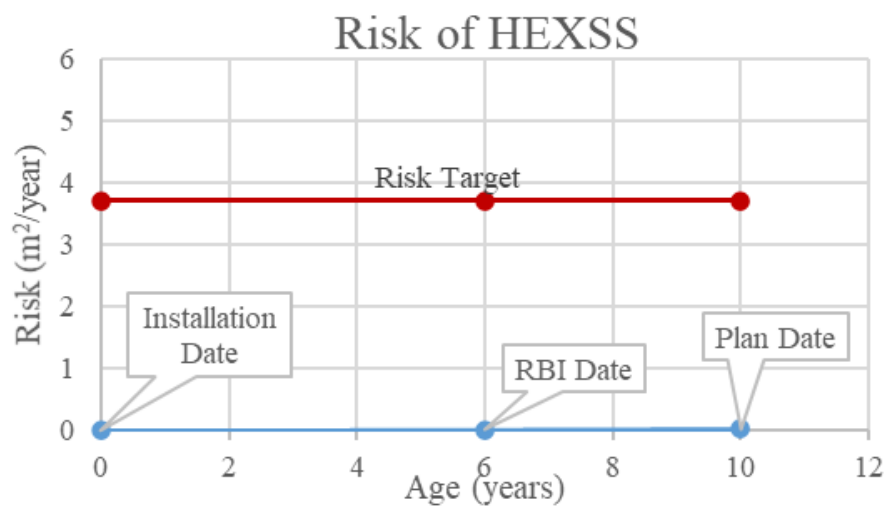

Figure. 4. Comparison Graphic of Risk Area (HEXSS)

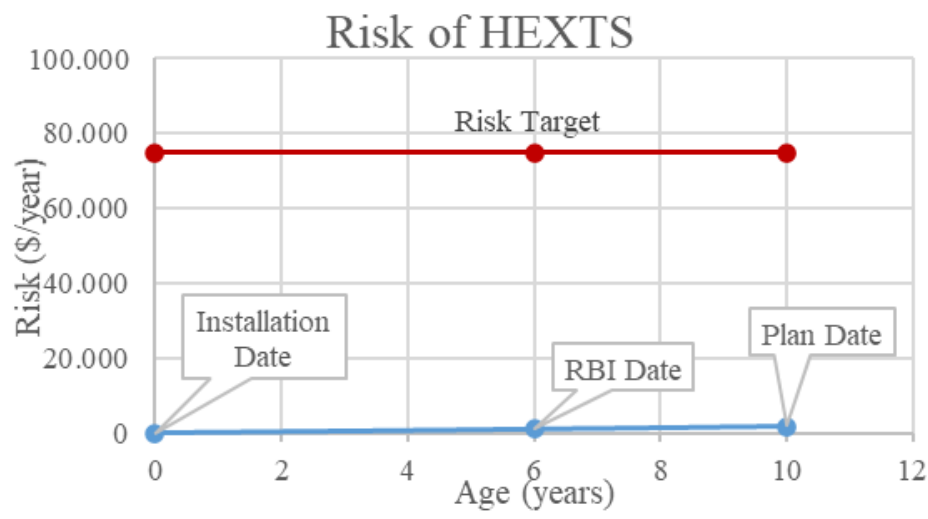

Figure. 5. Comparison of Graphic of Risk Financial (HEXTS)

Based on the results of the interpolation of the risk target value, it was found that the target date was very far since the last inspection was carried out. The results of the analysis of the determination of the inspection schedule can be seen in Figure 4 and Figure 5 which show the graph of each HEXSS and HEXTS component.
For this reason, the determination of the inspection schedule uses intervals of 10 years (internal inspection) and 5 years (external inspection) since the last inspection was carried out [10], wherein this case study the last inspection was during the installation, at 1 June 2014. Based on these assumptions, the date on

TABLE 9.

INSPECTION PLANNING OF AMINE REBOILER RECOMMENDATION

\begin{tabular}{|c|c|c|c|c|}
\hline Damage Factor & Effectiveness & Description & HEXSS Due Date & HEXTS Due Date \\
\hline Local Thinning & $\mathrm{C}$ & $\begin{array}{l}\text { For the total surface area: } \\
\text { 1. }>50 \% \text { Visual Examination } \\
\text { AND } \\
\text { 2. } 100 \% \text { follow up at locally thinned areas }\end{array}$ & $1 / 1 / 2024$ & $1 / 1 / 2024$ \\
\hline SCC-Amine Cracking & $\mathrm{C}$ & $\begin{array}{l}\text { For selected welds/weld area: } \\
\text { 1. }>35 \% \text { WFMT/ACFM } \\
\text { AND } \\
\text { 2. } 100 \% \text { UT follow up of all relevant indications }\end{array}$ & $1 / 1 / 2024$ & $1 / 1 / 2024$ \\
\hline $\begin{array}{l}\text { SCC-Sulfide Stress } \\
\text { Cracking }\end{array}$ & $\mathrm{C}$ & $\begin{array}{l}\text { For selected welds/weld area: } \\
\text { 1. }>35 \% \text { WFMT/ACFM } \\
\text { AND } \\
\text { 2. } 100 \% \text { UT follow up of all relevant indications }\end{array}$ & $1 / 1 / 2024$ & $1 / 1 / 2024$ \\
\hline $\begin{array}{l}\mathrm{SCC}-\mathrm{HIC} / \mathrm{SOHIC}- \\
\mathrm{H}_{2} \mathrm{~S}\end{array}$ & $\mathrm{C}$ & $\begin{array}{l}\text { For the total surface area: } \\
\text { 1. }>50 \% \text { WFMT/ACFM } \\
\text { 2. UT Follow-up of indications } \\
\text { 3. } 100 \% 100 \% \text { Visual of total surface area } \\
\text { OR } \\
\text { 1. }>35 \% \text { A or C scan with straight beam followed by } \\
\text { TOFD/Shear Wave } \\
\text { 2. } 100 \% \text { Visual examination }\end{array}$ & $1 / 1 / 2024$ & $1 / 1 / 2024$ \\
\hline $\begin{array}{l}\text { Corrosion Under } \\
\text { Insulation }\end{array}$ & $\mathrm{C}$ & $\begin{array}{l}\text { For the total surface area: } \\
1.100 \% \text { external visual inspection prior to removal } \\
\text { of insulation } \\
\text { 2. Remove }>25 \% \text { of suspect areas } \\
\text { 3. } 100 \% \text { visual inspection as follow-up of corroded } \\
\text { areas with UT/RT/pit gauge }\end{array}$ & $1 / 1 / 2024$ & - \\
\hline
\end{tabular}


which the inspection is to be carried out next is January 1, 2024.

b. Inspection Methods

The results of the recommended inspection method based on the damage factor to the equipment can be seen in Table 9, while the recommended inspection points for the Amine Reboiler due to the potential for corrosion are on the nozzle, shell, head, and tubing parts [11].

\section{CONCLUSION}

Based on the results of the RBI analysis on amine reboiler, it can be concluded that:

1. Failure probability $(\mathrm{PoF})$ values for the HEXSS component at the time of RBI date $(01 / 01 / 2020)$ and RBI plan date $(01 / 01 / 2024)$ were $2.080 \mathrm{E}-03$ failure/year and 4.646E-03 failure/year with a failure consequence value $(\mathrm{CoF})$ based on the affected area of $4.56 \mathrm{~m}^{2}$. As for the HEXTS component, the PoF value at the time of the RBI date and RBI plan date is $4.758 \mathrm{E}-03$ failure/year and $8.454 \mathrm{E}-03$ failure/year, with the $\mathrm{CoF}$ value based on the financial impact is $\$ 218,675.43$.

2. The level of risk for the HEXSS component on the RBI date and RBI plan date is low risk and medium risk respectively, with each risk values are $9.48 \mathrm{E}-03 \mathrm{~m}^{2} /$ year and $2.12 \mathrm{E}-02 \mathrm{~m}^{2} /$ year. Meanwhile, the risk level for the HEXTS component at the RBI date and RBI plan date are both at the medium-high risk level with risk values respectively are \$1040.49/year and $\$ 1848.59 /$ year.

3. The recommended date for the next inspection schedule is January $1^{\text {st }}$, 2024. The recommended inspection methods are Visual Testing (VT), Ultrasonic Testing (UT) / Radiographic Testing (RT), and Magnetic Particle Testing / Eddy Current Testing, with the effectiveness of the inspection being in the category $\mathrm{C}$. The inspection planning is designed to include measuring the wall thickness at points that have a chance of corrosion. In the Amine Reboiler analysis, several recommended points are located on the shell, head, nozzle, and tubing.

\section{ACKNOWLEDGMENTS}

A lot of gratitude given to the lecturers and members of Marine Operation and Maintenance (MOM) Laboratory.

\section{REFERENCES}

[1] Kementerian Keuangan, "Laporan Kementerian Keuangan 2019," Jakarta, 2019.

[2] H. Fadilah, "Analisis Reboiler Tipe Shell dan Tube untuk Sistem Destilasi Bioetanol yang Terintegrasi dengan Turbin Gas Mikro Bioenergi Proto X-2," Universitas Indonesia, Jakarta, 2012.
[3] S. Mokhatab and W. A. Poe, Handbook of Natural Gas Transmission and Processing, Burlington: Elsevier Inc., 2006.

[4] R. K. Shah and D. P. Sekulic, Fundamental of Heat Exchanger Design, New Jersey: John Wiley \& Sons, Inc., 2003.

[5] U.S. Chemical Safety and Hazard Investigation Board, "Tesoro Anacortes Refinery Investigation Report," CSB, Washington, D.C., 2014.

[6] American Petroleum Institute, API Recommended Practice 580: Risk-based Inspection, 3rd Edition, Washington, D.C.: API Publishing Services, 2016.

[7] American Petroleum Institute, API Recommended Practice 581: Risk Based Inspection Technology, 3rd Edition, Washington, D.C.: API Publishing Service, 2016.

[8] D. Priyanta, N. Siswantoro and A. M. Megawan, "Risk Based Inspection of Gas-Cooling Heat Exchanger," International Journal of Marine Engineering Innovation and Research, vol. I, no. 4, pp 317-329, 2017.

[9] A. C. Murariu and N. Pasca, "Application of Risk Based Inspection to Heat Exchangers of A Chemical Plant for Heavy Water Production," in VIth Edition of the International Conference The Academic Days of the Academy of Technical Sciences of Romania, Romania, 2013.

[10]N. Deshpande, "Failure Analysis of Heat Exchanger Tube Due to Corrosion," International Research Journal of Advanced Engineering and Science, vol. III, no. 1, pp. 133-136, 2018.

[11]American Petroleum Institute, API 510: Pressure Vessel Inspection Code Maintenance Inspection, Rating, Repair, and Alteration, 10th Edition, Washington, D.C.: API Publishing Service, 2014.

[12] American Petroleum Institute, API Recommended Practice 572 Inspection of Pressure Vessels (Towers, Drums, Reactors, Heat Exchangers, and Condensers, 2nd Edition, Washington, D.C.: API Publishing Service, 2001. 